Www.jmscr.igmpublication.org

Impact Factor 5.84

Index Copernicus Value: 83.27

ISSN (e)-2347-176x ISSN (p) 2455-0450

crossref DOI: _https://dx.doi.org/10.18535/jmscr/v5i7.158

Journal Of Medical Science And Clinical Research

IGM Publication

An Official Publication of IGM Publication

\title{
Assessment of Allergic Rhinitis in North Indian Population
}

\author{
Authors \\ Dr Tribhuban Kumar ${ }^{1}$, Dr Ratnesh Kumar ${ }^{2}$ \\ ${ }^{1}$ Assistant Professor, Department of ENT, Patna Medical College \& Hospital, Patna, Bihar \\ ${ }^{2}$ Senior Resident, Department of ENT, Patna Medical College \& Hospital, Patna, Bihar \\ Corresponding Author \\ Dr Ratnesh Kumar \\ Senior Resident, Department of ENT, Patna Medical College \& Hospital, Patna, Bihar
}

\begin{abstract}
Allergic rhinitis is typically triggered by environmental allergens such as pollen, pet hair, dust, or mold. Inherited genetics and environmental exposures contribute to the development of allergies. Growing up on a farm and having multiple siblings decreases the risk. The underlying mechanism involves IgE antibodies attaching to the allergen and causing the release of inflammatory chemicals such as histamine from mast cells.

The patients admitted to ENT department of Patna Medical College and Hospital was considered in the study. The approval of the Ethical Committee is taken from the Hospital. The written consent also obtained from the patients. The total 50 were included in the study.

Comorbidities, associating allergic rhinitis, were examined and quality of life summarily assessed, as, subjective degree of disturbance to sleep and daily life activities. Nasal mucosa scraping was taken, from surface of middle third of inferior turbinate with wooden rhino probe and eosinophilic/basophilic infiltration was inspected, to objective ascertaining of allergic rhinitis.

Allergic rhinitis is a highly prevalent yet underappreciated inflammatory disorder which affects not only the nasal mucosa but also other contiguous mucosa. Although most patients presented with nasal symptoms, ophthalmic and pharyngeal symptoms were commonly presented. A significant percentage of patients had aural and respiratory comorbidities. Sleep disturbances were seen in a significant number of allergic patients. Thus, in a patient with Allergic rhinitis special attention has to be given to the ear, throat, eye, and asthmatic aspects.
\end{abstract}

Keywords: Allergic rhinitis, North Indian Population, Comorbidities etc.

\section{INTRODUCTION}

Allergic rhinitis, also known as hay fever, is a type of inflammation in the nose which occurs when the immune system overreacts to allergens in the air. ${ }^{[6]}$ Signs and symptoms include a runny or stuffy nose, sneezing, red, itchy, and watery eyes, and swelling around the eyes. ${ }^{[1]}$ The fluid from the nose is usually clear. Symptom onset is often within minutes following exposure and they can affect sleep, the ability to work, and the ability to concentrate at school. ${ }^{[2]}$ Those whose symptoms are due to pollen typically develop symptoms during specific times of the year. ${ }^{[3]}$ Many people with allergic rhinitis also have 
asthma, allergic conjunctivitis, or atopic dermatitis. ${ }^{[2]}$

Allergic rhinitis is typically triggered by environmental allergens such as pollen, pet hair, dust, or mold. Inherited genetics and environmental exposures contribute to the development of allergies. ${ }^{[3]}$ Growing up on a farm and having multiple siblings decreases the risk. The underlying mechanism involves $\operatorname{IgE}$ antibodies attaching to the allergen and causing the release of inflammatory chemicals such as histamine from mast cells. ${ }^{[2]}$ Diagnosis is usually based on a medical history in combination with a skin prick test or blood tests for allergen-specific IgE antibodies. These tests, however, are sometimes falsely positive. ${ }^{[4]}$ The symptoms of allergies resemble those of the common cold; however, they often last for more than two weeks and typically do not include a fever. ${ }^{[3]}$

Exposure to animals in early life might reduce the risk of developing allergies to them later. ${ }^{[3]} \mathrm{A}$ number of medications may improve symptoms including nasal steroids, antihistamines such as diphenhydramine, cromolyn sodium, and leukotriene receptor antagonists such as montelukast. $^{[5]}$ Medications are, however, not sufficient or are associated with side effects in many people. ${ }^{[2]}$ Exposing people to larger and larger amounts of allergen, known as allergen immunotherapy, is often effective. The allergen may be given as injections just under the skin or as a tablet under the tongue. Treatment typically lasts three to five years after which benefits may be prolonged. $^{[6]}$

Allergic rhinitis is the type of allergy that affects the greatest number of people. ${ }^{[8]}$ In Western countries, between $10-30 \%$ of people are affected in a given year. ${ }^{[2][7]}$ It is most common between the ages of twenty and forty. ${ }^{[2]}$ The first accurate description is from the 10th century physician Rhazes. ${ }^{[9]}$ Pollen was identified as the cause in 1859 by Charles Blackley. ${ }^{[10]}$ In 1906, the mechanism was determined by Clemens von Pirquet. ${ }^{[8]}$ The link with hay came about due to an early (and incorrect) theory that the symptoms were brought about by the smell of new hay. ${ }^{[11][12]}$ The characteristic symptoms of allergic rhinitis are: rhinorrhea (excess nasal secretion), itching, sneezing fits, and nasal congestion and obstruction. ${ }^{[13]}$ Characteristic physical findings include conjunctival swelling and erythema, eyelid swelling, lower eyelid venous stasis (rings under the eyes known as "allergic shiners"), swollen nasal turbinates, and middle ear effusion. ${ }^{[14]}$

There can also be behavioural signs; in order to relieve the irritation or flow of mucus, people may wipe or rub their nose with the palm of their hand in an upward motion: an action known as the "nasal salute" or the "allergic salute". This may result in a crease running across the nose (or above each nostril if only one side of the nose is wiped at a time), commonly referred to as the "transverse nasal crease", and can lead to permanent physical deformity if repeated enough. ${ }^{[15]}$

People might also find that cross-reactivity occurs. ${ }^{[16]}$ For example, someone allergic to birch pollen may also find that he/she has an allergic reaction to the skin of apples or potatoes. ${ }^{[17]} \mathrm{A}$ clear sign of this is the occurrence of an itchy throat after eating an apple or sneezing when peeling potatoes or apples. This occurs because of similarities in the proteins of the pollen and the food. ${ }^{[18]}$ There are many cross-reacting substances. Hay fever is not a true fever, meaning it does not cause a core body temperature in the fever over 37.5-38. $3^{\circ} \mathrm{C}\left(99.5-100.9^{\circ} \mathrm{F}\right)$.

Allergic rhinitis triggered by the pollens of specific seasonal plants is commonly known as "hay fever", because it is most prevalent during haying season. However, it is possible to have allergic rhinitis throughout the year. The pollen that causes hay fever varies between individuals and from region to region; in general, the tiny, hardly visible pollens of wind-pollinated plants are the predominant cause. Pollens of insectpollinated plants are too large to remain airborne and pose no risk. Examples of plants commonly responsible for hay fever include: 
- Trees: such as pine (Pinus), birch (Betula), alder (Alnus), cedar, hazel (Corylus), hornbeam (Carpinus), horse chestnut (Aesculus), willow (Salix), poplar (Populus), plane (Platanus), linden/lime (Tilia), and olive (Olea). In northern latitudes, birch is considered to be the most common allergenic tree pollen, with an estimated $15-20 \%$ of people with hay fever sensitive to birch pollen grains. A major antigen in these is a protein called Bet V I. Olive pollen is most predominant in Mediterranean regions. Hay fever in Japan is caused primarily by sugi (Cryptomeria japonica) and hinoki (Chamaecyparisobtusa) tree pollen.

- "Allergy friendly" trees include: ash (female only), red maple, yellow poplar, dogwood, magnolia, double-flowered cherry, fir, spruce, and flowering plum. ${ }^{[19]}$

- Grasses (Family Poaceae): especially ryegrass (Lolium sp.) and timothy (Phleumpratense). An estimated 90\% of people with hay fever are allergic to grass pollen.

- Weeds: ragweed (Ambrosia), plantain (Plantago), nettle/parietaria (Urticaceae), mugwort (Artemisia Vulgaris), Fat hen (Chenopodium), and sorrel/dock (Rumex)

- Allergic rhinitis may also be caused by allergy to Balsam of Peru, which is in various fragrances and other products. ${ }^{[20-}$ 22].

- The study was planned to evaluate theprofile of allergic rhinitis related with co-morbidity, treatment and outcome was assessed to generate clinical evidence base, for improved practice.

\section{METHODOLOGY}

The patients admitted to ENT department of Patna Medical College and Hospital was considered in the study. The approval of the Ethical Committee is taken from the Hospital. The written consent also obtained from the patients. The total 50 were included in the study.

Following is the inclusion and exclusion criteria for the both study group.

\section{Inclusion criteria}

1. Patients presenting with history suggestive of AR such as rhinorrhea, sneezing, itching, and nasal obstruction

2. Patients with clinical evidence of AR such as bilateral pale ITH or AEC $>350$.

\section{Exclusion criteria}

1. Patients with rhinitis of infectious origin

2. Patients with non-AR such as vasomotor rhinitis, rhinitis medicamentosa

3. Patients refusing consent for nasal biopsy

4. Atrophic rhinitis

Comorbidities, associating allergic rhinitis, were examined and quality of life summarily assessed, as, subjective degree of disturbance to sleep and daily life activities. Nasal mucosa scraping was taken, from surface of middle third of inferior turbinate with wooden rhinoprobe and eosinophilic/basophilic infiltration was inspected, to objective ascertaining of allergic rhinitis ${ }^{[23-24]}$. Cases without co-morbidity were conventionally managed, with nasal fluticasone and oral cetrizine treatment. For co-morbidities, suitable surgical care was given.

\section{RESULTS \& DISCUSSION}

The data from the 50 allergic rhinitis patients were collected and presented as below. The age, sex, duration of symptoms were recorded.

Table 1: Age of the patients in both study groups

\begin{tabular}{|c|c|}
\hline Age in years & Total patients \\
\hline $10-20$ & 10 \\
\hline $20-30$ & 6 \\
\hline $31-40$ & 14 \\
\hline $41-50$ & 12 \\
\hline $51-60$ & 8 \\
\hline Total & 50 \\
\hline
\end{tabular}

The data in the table 1 indicates the maximum allergic rhinitis patients are seen in the age group of above 41 to 60 years. 
Table 2: Male \& Female Ratio

\begin{tabular}{|c|c|}
\hline Gender & Total patients \\
\hline Males & 32 \\
\hline Females & 18 \\
\hline Total & 50 \\
\hline
\end{tabular}

Table 3: Symptoms and Observed Cases

\begin{tabular}{|c|c|c|}
\hline Symptom & Number of Cases & Percentage \\
\hline Nasal blockage & 40 & 80 \\
\hline Running nose & 33 & 66 \\
\hline Recurrent sneezing & 28 & 56 \\
\hline Nasal itching & 23 & 46 \\
\hline Eye itching/watering & 18 & 36 \\
\hline
\end{tabular}

Table 4: Co-morbidities, associated with allergic rhinitis

\begin{tabular}{|c|c|c|}
\hline Co-morbidities & Number of Cases & Percentage \\
\hline Recurrent tonsillitis & 26 & 52 \\
\hline Adenoid hypertrophy & 23 & 46 \\
\hline $\begin{array}{c}\text { Inferior turbinate } \\
\text { hypertrophy }\end{array}$ & 18 & 36 \\
\hline Nasal polyp & 6 & 12 \\
\hline Ear discharge & 6 & 12 \\
\hline Sinusitis & 2 & 4 \\
\hline
\end{tabular}

The proposed causes for proliferation in occurrence of allergic rhinitis, are climate factors, dietary transition, pollution etc. Allergic rhinitis with its attendant complications is a common condition today, affecting all the age groups with more prediction in the younger generation. The mean age of the patients who entered our study was 27.04 years which is in accordance with the studies of Alsowaidi ${ }^{[25]}$ (2010) 30 years, Viinanen ${ }^{[26]}$ (2005) 30.2 years, and Valero ${ }^{[27]}$ (2007) 32.3 years. One reason can be that AR affects early. In addition, the lifestyle and activity in this age group, who are more active compared to older age group, will increase the chances of bringing them into contact with a wide variety of allergens.

Typical symptoms of Allergic rhinitis include sneezing, itching, clear rhinorrhea, and congestion. Patients may also complain of red, itchy eyes, along with itchy throat and ears. In this study, all the patients had nasal symptoms of Allergic rhinitis whereas almost half of them had ophthalmic symptoms and pharyngeal symptoms.

\section{CONCLUSION}

Allergic rhinitis is a highly prevalent yet underappreciated inflammatory disorder which affects not only the nasal mucosa but also other contiguous mucosa. Although most patients presented with nasal symptoms, ophthalmic and pharyngeal symptoms were commonly presented. A significant percentage of patients had aural and respiratory comorbidities. Sleep disturbances were seen in a significant number of allergic patients. Thus, in a patient with Allergic rhinitis special attention has to be given to the ear, throat, eye, and asthmatic aspects.

\section{REFERENCES}

1. "Environmental Allergies: Symptoms". NIAID. April 22, 2015. Retrieved 19 June 2015.

2. Wheatley, LM; Togias, A (29 January 2015). "Clinical practice. Allergic rhinitis.". The New England Journal of Medicine. 372 (5): 456-63. PMC 4324099 PMID 25629743. doi:10.1056/NEJMcp1412282.

3. "Cause of Environmental Allergies". NIAID. April 22, 2015. Retrieved 17 June 2015.

4. "Environmental Allergies: Diagnosis". NIAID. May 12, 2015. Retrieved 19 June 2015.

5. "Environmental Allergies: Treatments". NIAID. April 22, 2015. Retrieved 17 June2015.

6. "Immunotherapy for Environmental Allergies". NIAID. May 12, 2015. Retrieved 19 June 2015.

7. Dykewicz MS, Hamilos DL (February 2010). "Rhinitis and sinusitis". The Journal of Allergy and Clinical Immunology. 125 (2 Suppl 2): S103-15. PMID 20176255. doi:10.1016/j.jaci.2009.12.989.

8. Fireman, Philip (2002). Pediatric otolaryngology vol 2. (4th ed.). Philadelphia, Pa.: W. B. Saunders. p. 1065. ISBN 9789997619846. 
9. Colgan, Richard (2009). Advice to the young physician on the art of medicine. New York: Springer. p. 31. ISBN 9781441910349.

10. Justin Parkinson (1 July 2014). "John Bostock: The man who 'discovered' hay fever". BBC News Magazine. Retrieved 19 June 2015.

11. "Dr. Marshall Hall on Diseases of the Respiratory System; III. Hay Asthma". The Lancet: 245. May 19, 1838. doi:10.1016/S0140-6736(02)95895-2.

12. History of Allergy. Karger Medical and Scientific Publishers. 2014. p. 62. ISBN 9783318021950.

13. Sur DK, Scandale S (June 2010). "Treatment of allergic rhinitis". Am Fam Physician. 81 (12): 1440-6. PMID 20540482.

14. Valet RS, Fahrenholz JM (2009). "Allergic rhinitis: update on diagnosis". Consultant. 49: 610-3.

15. Pray, W. Steven (2005). Nonprescription Product Therapeutics. p. 221: Lippincott Williams \& Wilkins. ISBN 0781734983.

16. Czaja-Bulsa G, Bachórska J (1998). "[Food allergy in children with pollinosis in the Western sea coast region]". Pol Merkur Lekarski. 5 (30): 338-40. PMID 10101519.

17. Yamamoto T, Asakura K, Shirasaki H, Himi T, Ogasawara H, Narita S, Kataura A (2005). "[Relationship between pollen allergy and oral allergy syndrome]". Nippon Jibiinkoka Gakkai Kaiho. 108 (10): 971-9. PMID 16285612. doi:10.3950/jibiinkoka.108.971.

18. Malandain H (2003). "[Allergies associated with both food and pollen]". AllergImmunol (Paris). 35 (7): 253-6. PMID 14626714.

19. "Allergy Friendly Trees". Forestry. about. com. 2014-03-05. Retrieved 2014-04-25.
20. Pamela Brooks (2012). The Daily Telegraph: Complete Guide to Allergies. ISBN 9781472103949. Retrieved 2014-04-27.

21. Denver Medical Times: Utah Medical Journal. Nevada Medicine. 2010-01-01. Retrieved 2014-04-27.

22. George Clinton Andrews; Anthony Nicholas Domonkos (1998-07-01). Diseases of the Skin: For Practitioners and Students. Retrieved 2014-04-27.

23. Miri S, Farid R, Akbari H, Amin R; Prevalence of allergic rhinitis and nasal smear eosinophilia in 11 to $15 \mathrm{yr}$-old children in Shiraz. Pediatr Allergy Immunol. 2006; 17(7):519-23.

24. Miller RE, Paradise JL, Friday GA, Fireman P, Voith D; The nasal smear for eosinophils. Its value in children with seasonal allergic rhinitis. Am J Dis Child. 1982; 136(11):1009-11.

25. Alsowaidi S, Abdulle A, Shehab A, Zuberbier T, Bernsen R. Allergic rhinitis: Prevalence and possible risk factors in a Gulf Arab population. Allergy 2010;65(2):208-12.

26. Viinanen A, Munhbayarlah S, Zevgee T, Narantsetseg L, Naidansuren TS, Koskenvuo M, et al. Prevalence of asthma, allergic rhinoconjunctivitis and allergic sensitization in Mongolia. Allergy 2005;60(11):1370-7.

27. Valero A, Alonso J, Antépara I, Baró E, Colás C, delCuvilloA, et al. Health-related quality of life in allergic rhinitis: Comparing the short form ESPRINT-15 and Mini RQLQ questionnaires. Allergy 2007;62(12):1372-8. 